\title{
Screening for Atrial Fibrillation in Relation to Stroke and Mortality Risk
}

\author{
Marco Proietti ${ }^{1,2,3}$ Giuseppe Boriani ${ }^{4}$ \\ ${ }^{1}$ Department of Clinical Sciences and Community Health, University \\ of Milan, Milan, Italy \\ ${ }^{2}$ Geriatric Unit, IRCCS Istituti Clinici Scientifici Maugeri, Milan, Italy \\ ${ }^{3}$ Liverpool Centre for Cardiovascular Science, University of Liverpool \\ and Liverpool Heart \& Chest Hospital, Liverpool, United Kingdom \\ ${ }^{4}$ Division of Cardiology, Department of Biomedical, Metabolic and \\ Neural Sciences, University of Modena and Reggio Emilia, Policlinico \\ di Modena, Modena, Italy
}

Thromb Haemost 2022;122:171-175.
Address for correspondence Marco Proietti, MD, PhD, FESC, FEHRA, Geriatric Unit, IRCCS Istituti Clinici Scientifici Maugeri, Via Camaldoli 64, 20138, Milan, Italy (e-mail: marco.proietti@unimi.it).

Giuseppe Boriani, MD, PhD, Division of Cardiology, Department of Biomedical, Metabolic and Neural Sciences, University of Modena and Reggio Emilia, Policlinico di Modena, Via del Pozzo, 71, 41124 Modena, Italy (e-mail: giuseppe.boriani@unimore.it).
There has been much advocacy for the implementation of screening strategies for asymptomatic atrial fibrillation $(\mathrm{AF}){ }^{1}$ given the high health care burden associated with this common arrhythmia. ${ }^{2}$ Importantly, AF can occur asymptomatically in up to $40 \%$ of the cases, even though no profound differences were reported between symptomatic and asymptomatic AF patients in terms of risk for adverse outcomes. ${ }^{3,4}$ Based on this evidence, implementing screening strategies to effectively identify unknown AF patients has highlighted how structured screening strategies are effective in identifying a higher number of high-risk AF patients needing the prescription of oral anticoagulants (OACs), and that using such strategies to increase OAC can be costeffective. ${ }^{5-7}$ Notwithstanding this, most of the studies reported thus far have only focused on the diagnostic yield related to the screening procedure and were not designed or powered to identify a significant clinical benefit in reducing adverse events in screened patients compared with those incidentally diagnosed with $\mathrm{AF}^{1}{ }^{1}$ On the basis of this lack of evidence, in 2018 the United States Preventive Services Task Force (USPSTF) released a statement which still did not recommend the use of large-scale systematic screening strategies to identify AF patients. ${ }^{8,9}$

In this issue of Thrombosis and Haemostasis, Wallenhorst and colleagues present an interesting and topical analysis ${ }^{10}$ derived from the United Kingdom Clinical Practice Research Datalink, linked to the Hospital Episodes Statistics and the Office for National Statistics to gather information regarding hospital admissions and mortality data. In this analysis using International Classification of Diseases-10th Revision codes, the authors analyzed 22,035 adult (18-84 years old) subjects with incident AF from January 1, 2001 to October 31, 2009 categorized according to the mode of AF detection. Hence, the patients were divided as follows: (1) asymptomatic incidentally detected ambulatory AF (AA-AF) [ $N=5,409,24.5 \%$ )]; (2) symptomatic ambulatory AF (SA-AF) [ $N=5,913,26.8 \%]$; (3) AF as primary hospital discharge diagnosis ( $\mathrm{PH}-\mathrm{AF}$ ) $[N=4,989$, 22.6\%); (4) AF as nonprimary hospital discharge diagnosis (Non-PH-AF) [ $N=26.0 \%]$. The study cohort was then analyzed and compared with 23,605 non-AF matched patients, regarding the occurrence of stroke and all-cause death during longterm follow-up. At baseline, AA-AF patients were found to be less affected by comorbidities, with an overall low thromboembolic risk, similarly to non-AF patients. Conversely, the non$\mathrm{PH}-\mathrm{AF}$ group showed the highest burden of comorbidities and the highest level of thromboembolic risk. SA-AF and PH-AF patients showed a mixed clinical profile being both moderately comorbid, but with PH-AF ones being younger and with the lowest thromboembolic risk. Over a 3-year follow-up, while the non-AF group was associated to lower risk of stroke occurrence, in a fully adjusted competitive risk analysis compared with the AA-AF group, all the other three groups (SA-AF, $\mathrm{PH}-\mathrm{AF}$, and Non-PH-AF) reported no differences in the association with stroke events, as compared with the asymptomatic patients. ${ }^{10}$ Similar results were found when restricting the observation to high-risk patients only (males with $\mathrm{CHA}_{2} \mathrm{DS}_{2}$ VASc $\geq 2$ and females with $\mathrm{CHA}_{2} \mathrm{DS}_{2}$-VASc $\geq 3$ ).

Non-AF subjects were associated with a lower risk and the SA-AF and PH-AF ones showed no difference in association with all-cause death; however, non-PH-AF patients were associated with a higher risk of all-cause death compared with asymptomatic patients. Notably, the rate of OAC prescription was generally low ( $29 \%)$, with no differences between low- and high-risk patients and both AA-AF and SA-AF having the same received

July 25, 2021

accepted

July 27, 2021

published online

July 29, 2021 (c) 2021. Thieme. All rights reserved. Georg Thieme Verlag KG,

Rüdigerstraße 14,

70469 Stuttgart, Germany
DOI https://doi.org/ 10.1055/a-1562-0747. ISSN 0340-6245. 
OAC prevalence, while non-PH-AF subjects were markedly less treated with OAC ( 20\%).

This article allows us to highlight several important considerations regarding the modern management of $\mathrm{AF}$ patients. First, even in an unselected real-world cohort of subjects with first diagnosed AF, the proportion of patients with completely asymptomatic AF, which were only incidentally diagnosed, remains quite consistent, being around onequarter of the entire study cohort. Even though those patients appeared to be slightly less burdened with comorbidities, they still have an important thromboembolic risk with more than $70 \%$ with a $\mathrm{CHA}_{2} \mathrm{DS}_{2}$-VASc score $\geq 2$. Indeed, stroke risk changes with aging and incident comorbidities $^{11,12}$ and the burden of symptoms does not necessarily influence the risk of outcomes, even in those who never have been symptomatic ${ }^{4}$; hence, asymptomatic AF patients should not be less intensively treated in comparison with symptomatic subjects. ${ }^{3}$

Second, no differences in the risks of ischemic stroke between asymptomatic presentation of AF and other presentations have important clinical correlates regarding the application of opportunistic and/or systematic screening procedures in the general population. Indeed, those 5,409 asymptomatic patients who were found to be in AF were only accidentally diagnosed, mimicking what could be obtained by using an opportunistic screening applied to the entire population. If such patients had not been found in $\mathrm{AF}$, none of them could have been prescribed with OAC and then an even larger number of strokes would have been recorded. In the 2020 European Society of Cardiology (ESC) clinical guidelines, the need for screening has been strongly emphasized. ${ }^{13}$ Notwithstanding this, the ESC guidelines still recommend the use of opportunistic screening only in patients age $\geq 65$ years, even though with a "B" level of evidence, while the use of systematic screening is suggested to be considered in subjects $\geq 75$ years or with a high burden of stroke risk factors, again with a low quality of evidence (class II, level B). ${ }^{13}$ Currently the USPSTF is considering an update of its recommendations about screening strategies for $\mathrm{AF}$ (https:// www.uspreventiveservicestaskforce.org/uspstf/draft-recommendation/screening-atrial-fibrillation), and while this update is still ongoing, the evidence review still underlines that the direct evidence regarding the benefit of AF screening is still lacking, since no completed trials have assessed the benefits and harms of anticoagulation treatment among screen-detected AF. Consequently, systematic population screening for AF is still not recommended.

This situation appears paradoxical, given the large evidence regarding the positive diagnostic yield obtained by screening strategies ${ }^{1,5}$ and with a "major" scientific society recommending AF screening, even though with a low degree of direct evidence. This situation is due to the lack of solid data regarding the reduction of adverse clinical outcomes in subjects undergoing screening. Indeed, most of the studies published thus far focused exclusively on the diagnostic yield, not considering the long-term follow-up. Only few studies ( - Table 1, upper panel) currently report data about adverse events, again with conflicting and inconsistent data.
While some of the studies were small in size and reported a very low number of events with little or no differences between subjects diagnosed by screening and by usual care, ${ }^{14,15}$ other recent data seem to indicate a more significant benefit. The follow-up data from the STROKESTOP program, recently presented during the European Heart Rhythm Association 2021 online congress, showed a significant reduction of the composite outcome of adverse events, even though the Kaplan-Meier curves appeared to diverge only after 4 years of follow-up and with a small reduction in terms of relative risk. ${ }^{16}$ Conversely, the mSToPS trial ${ }^{17}$ seems to indicate a more important reduction of the risk over the 3 years of follow-up.

Additionally, more data are needed on the effects of screening on patient anxiety, as a consequence of a positive screening, as one of the criticisms raised by the first assessment done by the USPSTF, ${ }^{9}$ even if it is reasonable to expect that this can be easily managed through adequate patient information in the context of a clinically structured integrated approach. ${ }^{18}$ The current scenario suggests that even if the efficacy of screening in terms of diagnostic yield is quite solidly reported by several studies, the real impact on risk reduction is yet to be determined.

In the next few years, at least four large studies specifically investigating this issue would ultimately clarify whether to diagnose AF by screening campaigns would be useful or not ( - Table 1, lower panel). Indeed, the STROKESTOP II, ${ }^{19,20}$ the SAFER (ISRCTN Registry: ISRCTN72104369), the GUARD-AF (ClinicalTrials.gov: NCT04126486), and the HEARTLINE (ClinicalTrials.gov: NCT04126486) studies all are going to include very large number of patients and have been specifically conceived and powered to determine the impact of the screening strategies on clinical events.

Last, while the absence of a significant difference in allcause mortality between AA-AF, SA-AF, and PH-AF patients only emphasizes what we discussed above, regarding the evidence that those patients found in AF during hospitalization, but not as primary diagnosis, have a higher risk of all-cause death. This allows us to further emphasize the need for more structured management of "clinically complex AF" patients. The burden of clinical complexity is associated with AF pathophysiology and arrhythmia course over time, ${ }^{21}$ as well as with an increased risk of adverse outcomes (particularly all-cause death) ${ }^{22,23}$ and the prescription and quality of OAC therapy. ${ }^{22-24}$ Despite the significant uptake of OAC observed in recent years and the consequential reduction of stroke risk, ${ }^{25}$ the risk of allcause death has remained steadily high over the years, but has also increased in terms of absolute numbers. ${ }^{26,27}$ The recent ESC guidelines have underlined the importance to manage AF patients in an integrated and holistic way, by using the "Atrial fibrillation Better Care (ABC)" pathway, which was proposed to streamline the application of integrated care in AF patients ${ }^{28}$ with a major impact on reducing AF-related mortality, stroke, bleeding, and hospitalizations. ${ }^{29-32}$ Wider application of the ABC pathway, together with a better AF patient evaluation and characterization using the $4 \mathrm{~S}-\mathrm{AF}$ scheme, ${ }^{33}$ will help 
Table 1 Current and future studies about AF screening strategies and risk of adverse outcomes

\begin{tabular}{|c|c|c|c|c|c|}
\hline \multicolumn{6}{|l|}{ Current studies } \\
\hline Study & Year & Study design & $N$ & Outcomes & Main results \\
\hline REHEARSE-AF ${ }^{14}$ & 2017 & $\begin{array}{l}\geq 65 \text { year subjects with } \\
\mathrm{CH} \mathrm{A}_{2} \mathrm{DS}_{2}-\mathrm{VASC} \geq 2 \text { with no } \\
\mathrm{AF} \text { and no OAC or pacing } \\
\text { randomized to } 30 \text { seconds } \\
\text { single-lead handheld ECG twice } \\
\text { weekly or usual care }\end{array}$ & 1,004 & $\begin{array}{l}\text { Clinical events at } \\
1 \text { year FU }\end{array}$ & $\begin{array}{l}\text { Despite a numerically lower } \\
\text { number of most of the clinical } \\
\text { events examined, no } \\
\text { significant difference was } \\
\text { found between the two } \\
\text { groups }\end{array}$ \\
\hline Engdahl $^{15}$ & 2018 & $\begin{array}{l}\text { 74-75 year-old inhabitants from } \\
\text { one Swedish municipality } \\
\text { screened with } 12 \text {-lead ECG }+ \\
\text { handheld ECG for } 2 \text { weeks }\end{array}$ & 106 & $\begin{array}{l}\text { Ischemic stroke at } \\
5 \text { year FU }\end{array}$ & $\begin{array}{l}\text { At 5-year follow-up rates of } \\
\text { ischemic stroke significantly } \\
\text { decreased in the screening } \\
\text { area, while no changes were } \\
\text { found in a control geographical } \\
\text { area where no screening had } \\
\text { been performed }\end{array}$ \\
\hline STROKESTOP $^{16,34}$ & 2021 & $\begin{array}{l}\text { All residents from } 2 \text { Swedish } \\
\text { regions aged } 75-76 \text { randomized } \\
\text { to single-lead ECG twice daily for } \\
14 \text { days or usual care }\end{array}$ & 27,975 & $\begin{array}{l}\text { Combined endpoint } \\
\text { of ischemic stroke, } \\
\text { systemic embolism, } \\
\text { severe bleeding, } \\
\text { and all-cause death } \\
\text { at } 5 \text { year FU }\end{array}$ & $\begin{array}{l}\text { Subjects randomized to } \\
\text { screening had a lower risk of } \\
\text { the composite endpoint } \\
\text { throughout the follow-up } \\
\text { observation (HR: } 0.96,95 \% \\
\mathrm{Cl}: 0.920-0.999, p=0.045)^{\mathrm{a}}\end{array}$ \\
\hline mSToPS $^{17,35}$ & 2021 & $\begin{array}{l}\text { Claims database participants } \\
\geq 75 \text { years or males } \geq 55 \\
\text { years/females } \geq 65 \text { years with } \\
\text { one risk factor/comorbidity ran- } \\
\text { domized in } 1: 2 \text { ratio to ECG skin } \\
\text { patches monitoring for } 2 \text { weeks } \\
+2 \text { weeks after } 3 \text { months }\end{array}$ & 5,214 & $\begin{array}{l}\text { Combined endpoint } \\
\text { of ischemic stroke, } \\
\text { systemic embolism, } \\
\text { myocardial infarc- } \\
\text { tion, all-cause death } \\
\text { at } 3 \text { years FU }\end{array}$ & $\begin{array}{l}\text { Subjects randomized to } \\
\text { screening has a lower risk of } \\
\text { the combined endpoint ( } 8.4 \\
\text { vs. } 13.8 \text { per } 100 \text { person-years; } \\
\text { HR: } 0.53 \text {, } 95 \% \text { Cl: } 0.40-0.78 \text {; } \\
p<0.01)^{\text {b }}\end{array}$ \\
\hline \multicolumn{6}{|l|}{ Future studies } \\
\hline Study & Year & Study design & $N$ & Outcomes & Trial registration \\
\hline $\begin{array}{l}\text { STROKESTOP } \\
\text { II }^{19,20}\end{array}$ & 2017 & $\begin{array}{l}75-76 \text { years Stockholm region } \\
\text { inhabitants, randomized to } \\
\text { receive screening procedure or } \\
\text { usual care; subjects randomized } \\
\text { to screening were assigned to } \\
\text { handheld ECG monitoring either } \\
\text { intermittent for } 2 \text { weeks or } \\
\text { one-stop screening according to } \\
\text { NT-proBNP levels }\end{array}$ & 28,800 & $\begin{array}{l}\text { Primary outcome is } \\
\text { stroke or systemic } \\
\text { embolism; secondary } \\
\text { outcome is stroke, } \\
\text { systemic embolism, } \\
\text { or all-cause death } \\
\text { over } 5 \text { year FU }\end{array}$ & $\begin{array}{l}\text { ClinicalTrials.gov: } \\
\text { NCT02743416 }\end{array}$ \\
\hline SAFER & 2017 & $\begin{array}{l}\geq 70 \text { year subjects from a primary } \\
\text { care unit network randomized to } \\
\text { receive screening through a } \\
\text { single-lead handheld ECG } 4 \text { times } \\
\text { daily for } 3 \text { weeks; the study } \\
\text { comprises two feasibility phases } \\
\text { and one large interventional trial }\end{array}$ & 126,000 & $\begin{array}{l}\text { Ischemic and } \\
\text { haemorrhagic } \\
\text { stroke over } 5 \text { years } \\
\text { of FU }\end{array}$ & ISRCTN: ISRCTN72104369 \\
\hline GUARD-AF & 2019 & $\begin{array}{l}\geq 70 \text { year subjects from a } \\
\text { primary care unit network } \\
\text { randomized to receive screening } \\
\text { through an ECG skin patch with } \\
\text { no AF and no OAC }\end{array}$ & 52,000 & $\begin{array}{l}\text { Stroke leading to } \\
\text { hospitalisation and } \\
\text { bleeding leading to } \\
\text { hospitalisation over } \\
2 \text { year FU }\end{array}$ & $\begin{array}{l}\text { ClinicalTrials.gov: } \\
\text { NCT04126486 }\end{array}$ \\
\hline HEARTLINE & 2020 & $\begin{array}{l}\geq 65 \text { year-old subjects } \\
\text { randomized to receive screening } \\
\text { through a smart watch device } \\
\text { and a healthy heart engagement } \\
\text { program }\end{array}$ & 150,000 & $\begin{array}{l}\text { Composite of cere- } \\
\text { brovascular events } \\
\text { and all-cause death } \\
\text { over } 3 \text { years of FU }\end{array}$ & $\begin{array}{l}\text { ClinicalTrials.gov: } \\
\text { NCT04126486 }\end{array}$ \\
\hline
\end{tabular}

Abbreviations: AF, atrial fibrillation; $\mathrm{Cl}$, confidence interval; ECG, electrocardiogram; FU, follow-up; HR, hazard ratio; NT-proBNP, N-terminal prohormone of brain natriuretic peptide; OAC, oral anticoagulant.

a Data on outcomes presented at the European Heart Rhythm Association 2021 Online Congress, not yet fully published.

${ }^{b}$ Data on outcomes presented at the American Heart Association Scientific Sessions 2020, not yet fully published. 
improve our management and reduce the risk of adverse clinical events in AF patients.

\section{Conflict of Interest}

M.P. declares no conflict of interest. G.B. declares small speaker fee from Medtronic, Boston, Boehringer Ingelheim, and Bayer.

\section{References}

1 Freedman B, Camm J, Calkins H, et al; AF-Screen Collaborators. Screening for atrial fibrillation: a report of the AF-SCREEN International Collaboration. Circulation 2017;135(19):1851-1867

2 Burdett P, Lip GYH. Atrial fibrillation in the United Kingdom: predicting costs of an emerging epidemic recognising and forecasting the cost drivers of atrial fibrillation-related costs. Eur Heart J Qual Care Clin Outcomes 2020. Doi: 10.1093/ehjqcco/qcaa093

3 Xiong Q Proietti M, Senoo K, Lip GY. Asymptomatic versus symptomatic atrial fibrillation: a systematic review of age/gender differences and cardiovascular outcomes. Int J Cardiol 2015;191:172-177

4 Boriani G, Laroche C, Diemberger I, et al. Asymptomatic atrial fibrillation: clinical correlates, management, and outcomes in the EORP-AF Pilot General Registry. Am J Med 2015;128(05):509. e2-518.e2

5 Lowres N, Olivier J, Chao TF, et al. Estimated stroke risk, yield, and number needed to screen for atrial fibrillation detected through single time screening: a multicountry patient-level meta-analysis of 141,220 screened individuals. PLoS Med 2019;16(09): e1002903

6 Proietti M, Farcomeni A, Goethals P, et al; Belgian Heart Rhythm Week Investigators. Cost-effectiveness and screening performance of ECG handheld machine in a population screening programme: The Belgian Heart Rhythm Week screening programme. Eur J Prev Cardiol 2019;26(09):964-972

7 Jones NR, Crawford W, Yang Y, Hobbs FDR, Taylor CJ, Petrou S. A systematic review of economic aspects of service interventions to increase anticoagulation use in atrial fibrillation. Thromb Haemost 2021. Doi: $10.1055 / \mathrm{a}-1515-9428$

8 Curry SJ, Krist AH, Owens DK, et al; US Preventive Services Task Force. Screening for atrial fibrillation with electrocardiography: US preventive services task force recommendation statement. JAMA 2018;320(05):478-484

9 Jonas DE, Kahwati LC, Yun JDY, Middleton JC, Coker-Schwimmer $\mathrm{M}$, Asher GN. Screening for atrial fibrillation with electrocardiography: evidence report and systematic review for the US Preventive Services Task Force. JAMA 2018;320(05):485-498

10 Wallenhorst C, Martinez C, Freedman B. Risk of ischemic stroke in asymptomatic atrial fibrillation incidentally-detected in primary care compared with other clinical presentations. Thromb Haemost 2021. Doi: 10.1055/a-1541-3885

11 Chao TF, Liao JN, Tuan TC, et al. Incident co-morbidities in patients with atrial fibrillation initially with a CHA2DS2-VASc score of 0 (males) or 1 (females): implications for reassessment of stroke risk in initially 'low-risk' patients. Thromb Haemost 2019;119 (07):1162-1170

12 Choi SY, Kim MH, Lee KM, et al. Age-dependent anticoagulant therapy for atrial fibrillation patients with intermediate risk of ischemic stroke: a nationwide population-based study. Thromb Haemost 2020. Doi: 10.1055/a-1336-0476

13 Hindricks G, Potpara T, Dagres N, et al; ESC Scientific Document Group. 2020 ESC Guidelines for the diagnosis and management of atrial fibrillation developed in collaboration with the European Association for Cardio-Thoracic Surgery (EACTS): The Task Force for the diagnosis and management of atrial fibrillation of the European Society of Cardiology (ESC) developed with the special contribution of the European Heart Rhythm Association (EHRA) of the ESC. Eur Heart J 2021;42(05):373-498

14 Halcox JPJ, Wareham K, Cardew A, et al. Assessment of remote heart rhythm sampling using the AliveCor heart monitor to screen for atrial fibrillation: the REHEARSE-AF Study. Circulation 2017;136(19):1784-1794

15 Engdahl J, Holmén A, Rosenqvist M, Strömberg U. A prospective 5year follow-up after population-based systematic screening for atrial fibrillation. Europace 2018;20(FI_3):f306-f311

16 Svennberg E, Friberg L, Frykman V, et al. Benefits of systematic screening for atrial fibrillation - the STROKESTOP-study [Internet]. EHRA 2021 Late Break. Clin. Trials. 2021. Accessed August 4, 2021 at: https://esc365.escardio.org/Congress/232051-benefitsof-systematic-screening-for-atrial-fibrillation-the-strokestopstudy

17 Steinhubl SR, Waalen J, Sanyal A, et al. 3-year clinical outcomes in a nationwide, randomized, pragmatic clinical trial of atrial fibrillation screening - Mhealth screening to prevent strokes (mstops). (Abstract 18688) from Late-breaking science abstracts and featured science abstracts from the American Heart Association's scientific sessions 2020 and late-breaking abstracts in resuscitation science From the Resuscitation Science Symposium 2020. Circulation 2020;142(Suppl 24):e470-e500

18 Boriani G, Proietti M. Screening for atrial fibrillation: need for an integrated, structured approach. Eur J Intern Med 2019;67:33-35

19 Engdahl J, Svennberg E, Friberg L, et al. Stepwise mass screening for atrial fibrillation using N-terminal pro b-type natriuretic peptide: the STROKESTOP II study design. Europace 2017;19 (02):297-302

20 Kemp Gudmundsdottir K, Fredriksson T, Svennberg E, et al. Stepwise mass screening for atrial fibrillation using N-terminal B-type natriuretic peptide: the STROKESTOP II study. Europace 2020;22(01):24-32

21 Boriani G, Vitolo M, Diemberger I, et al. Optimizing indices of AF susceptibility and burden to evaluate AF severity, risk and outcomes. Cardiovasc Res 2021. Doi: 10.1093/cvr/cvab147

22 Proietti M, Marzona I, Vannini T, et al. Long-term relationship between atrial fibrillation, multimorbidity and oral anticoagulant drug use. Mayo Clin Proc 2019;94(12):2427-2436

23 Proietti M, Esteve-Pastor MA, Rivera-Caravaca JM, et al; FANTASIIA Study Investigators. Relationship between multimorbidity and outcomes in atrial fibrillation. Exp Gerontol 2021; 153:111482

24 Alexander KP, Brouwer MA, Mulder H, et al; ARISTOTLE Investigators. Outcomes of apixaban versus warfarin in patients with atrial fibrillation and multi-morbidity: insights from the ARISTOTLE trial. Am Heart J 2019;208:123-131

25 Cowan JC, Wu J, Hall M, Orlowski A, West RM, Gale CP. A 10 year study of hospitalized atrial fibrillation-related stroke in England and its association with uptake of oral anticoagulation. Eur Heart J 2018;39(32):2975-2983

26 Singh SM, Abdel-Qadir H, Pang A, et al. Population trends in allcause mortality and cause specific-death with incident atrial fibrillation. J Am Heart Assoc 2020;9(19):e016810

27 Dai H, Zhang Q, Much AA, et al. Global, regional, and national prevalence, incidence, mortality, and risk factors for atrial fibrillation, 1990-2017: results from the Global Burden of Disease Study 2017. Eur Heart J Qual Care Clin Outcomes 2020. Doi: 10.1093/ehjqcco/qcaa061

28 Lip GYH. The ABC pathway: an integrated approach to improve AF management. Nat Rev Cardiol 2017;14(11):627-628

29 Romiti GF, Pastori D, Rivera-Caravaca JM, et al. Adherence to the 'Atrial Fibrillation Better Care' pathway in patients with atrial fibrillation: impact on clinical outcomes-a systematic review and 
meta-analysis of 285,000 patients. Thromb Haemost 2021. Doi: 10.1055/a-1515-9630

30 Proietti M, Romiti GF, Olshansky B, Lane DA, Lip GYH. Comprehensive management with the $\mathrm{ABC}$ (Atrial Fibrillation Better Care) pathway in clinically complex patients with atrial fibrillation: a post hoc ancillary analysis from the AFFIRM trial. J Am Heart Assoc 2020;9(10):e014932

31 Proietti M, Vitolo M, Lip GYH. Integrated care and outcomes in patients with atrial fibrillation and comorbidities. Eur J Clin Invest 2021;51(06):e13498

32 Yoon M, Yang P-S, Jang E, et al. Improved population-based clinical outcomes of patients with atrial fibrillation by compliance with the simple $A B C$ (Atrial Fibrillation Better Care) pathway for integrated care management: a nationwide cohort study. Thromb Haemost 2019;119(10):1695-1703

33 Potpara TS, Lip GYH, Blomstrom-Lundqvist C, et al. The 4S-AF scheme (stroke risk; symptoms; severity of burden; substrate): a novel approach to in-depth characterization (rather than classification) of atrial fibrillation. Thromb Haemost 2021;121(03):270-278

34 Svennberg E, Engdahl J, Al-Khalili F, Friberg L, Frykman V, Rosenqvist M. Mass screening for untreated atrial fibrillation the STROKESTOP study. Circulation 2015;131(25):2176-2184

35 Steinhubl SR, Waalen J, Edwards AM, et al. Effect of a home-based wearable continuous ECG monitoring patch on detection of undiagnosed atrial fibrillation the mSToPS randomized clinical trial. JAMA 2018;320(02):146-155 